\title{
Avaliação dos resíduos sólidos e líquidos em concreteira
}

\author{
Evaluation of solid and liquids waste in a concrete industry \\ Fernando Ernesto Ucker', Anna Paula Ferreira Batista Goldfeld², Marcelo Tsuyoshi Haraguchi \\ Felipe Correa Veloso dos Santos ${ }^{3}$, Átila Reis ${ }^{3}$, Pedro Daniel da Cunha Kemerich ${ }^{3}$ \\ 'Doutorando em Agronomia pela Universidade Federal de Goiás \\ ${ }^{2}$ Mestranda em Agronomia pela Universidade Federal de Goiás \\ 3Universidade Federal de Goiás
}

\section{Resumo}

Este trabalho teve como objetivo propor alternativas para a minimização dos impactos ambientais causados pela geração de resíduos sólidos e líquidos a partir da lavagem de caminhões em uma indústria de concreto no município de Santa Maria - RS. Para a análise dos resíduos líquidos foram coletadas amostras nos meses de junho a outubro de 2009, em cinco pontos pré-definidos. Os valores obtidos pelas análises foram comparados com os resultados da amostra testemunha e os valores determinados pela NBR 13.696 (ABNT, 1997). A avaliação destes parâmetros apresentou a real eficiência dos decantadores já instalados na Empresa. Com isto, foi possível verificar a necessidade de se projetar um novo dimensionamento do sistema. O resíduo (lodo) proveniente dos decantadores já implantados na empresa foi removido com uma pá, seco ao ar e em câmara úmida, peneirado e incorporado na argamassa, substituindo-se parte da areia por porcentagens de $10 \%, 25 \%$ e $50 \%$. Os corpos-de-prova foram rompidos aos 7, 14 e 28 dias de cura. O efluente apresentou uma grande disparidade entre a amostra testemunho (poço artesiano) e a amostra no final do sistema de tratamento. Em relação aos resíduos sólidos, a incorporação do lodo gerado na indústria pode significar a redução de um impacto ambiental, contribuindo assim para um desenvolvimento sustentável, onde não será desperdiçado nenhum material gerado.

Palavras-chave: lodo; argamassa; impacto ambiental

\begin{abstract}
This work aimed to propose alternatives to minimize environmental impacts caused by the generation of solid and liquid waste from the truck wash in a concrete industry in the municipality of Santa Maria - RS. For the analysis of wastewater samples were collected from June to October 2009, in five pre-defined points. The values obtained by the analysis were compared with the results of the control sample and the values determined by NBR 13.696 (ABNT, 1997). The evaluation of theses parameters showed the actual efficiency of decanters already installer in the Company. With this, was found the need to design a new system. The residue (sludge) from the decanters already deployed in the enterprise was removed with a shovel, and air dried in a moist chamber incorporated in the mortar and sieved by replacing the sand by percentages of $10 \%, 25 \%$ and $50 \%$. The bodies of the specimens were broken at 7, 14 and 28 days of healing. The effluent showed a large disparity between the control sample (borehole) and the end of the sample treatment system. Regarding solid waste, incorporate the sludge generated in the industry can mean the reduction of environmental impact, thereby contributing to sustainable development, where there will be no wasted material generated.
\end{abstract}

Keywords: sludge; mortar; environmental impacts. 


\section{INTRODUÇÃO}

Para suprir as necessidades geradas pelo crescimento desordenado da população mundial, a construção civil atua direta e indiretamente no meio ambiente, gerando impactos positivos e principalmente negativos. A indústria de concreto age intensamente no mercado, fornecendo o material necessário para a fabricação principalmente de novas moradias. Porém, para a fabricação e uso do concreto, alguns impactos ambientais ocorrem, como a geração de resíduos, sejam eles sólidos ou líquidos, provenientes, por exemplo, da lavagem dos caminhões responsáveis pelo transporte do concreto.

Segundo Dias (2010) a retirada dos recursos naturais para a incorporação na matéria-prima principal da construção civil, o concreto, chega a $50 \%$ em todo o mundo, sendo assim um resultado que necessite de muito estudo para a diminuição dos impactos gerados.

Atualmente, na busca de maior eficiência e menor geração de resíduos, tem-se introduzido o conceito de tecnologias limpas, que devem, de acordo com o boletim da Fundação Vanzolini (2000), reunir as seguintes características: utilizar compostos não agressivos e de baixo custo, exigir menor consumo de reagentes, produzindo pouco ou nenhum resíduo e permitir controle mais simples e eficiente de sua eliminação. E ainda, Fontenele, Guimarães e Sabiá (2006) definem como um dos princípios da tecnologia limpa, o emprego de técnicas de reutilização, reciclagem e reaproveitamento de materiais.

A produção mais limpa faz parte das novas estratégias de administração industrial, pois grandes esforços são empregados para o seu alcance
(SCHENINI et al., 2005). As empresas ecologicamente corretas, dentre seus objetivos, buscam a preservação e a sustentabilidade ambiental. Isto tem levado os gestores a repensar os seus processamentos industriais, buscando novas tecnologias e alterações em seus produtos, de modo a minimizar a geração de emissões e resíduos.

Embora a atividade industrial do município seja de baixa intensidade, Santa Maria - RS possui uma indústria de construção civil bastante ativa, principalmente pela demanda de novas moradias para acomodar as pessoas que vem à cidade para ocupar cargos federais e vagas no ensino médio e superior. Esta intensa atividade pode, muitas vezes, trazer sérios impactos ao meio ambiente, como contaminação de recursos hídricos e do solo.

Em direção a este pensamento, o objetivo deste trabalho foi propor alternativas para a minimização dos impactos ambientais causados pela geração de resíduos sólidos e líquidos gerados a partir da lavagem de caminhões em uma indústria de concreto no município de Santa Maria - RS.

\section{MATERIAL E MÉTODOS}

O presente trabalho foi realizado em uma empresa localizada no município de Santa Maria, no centro do Estado do Rio Grande do Sul. A empresa possui um sistema para lavagem de caminhões, lavagem esta realizada por fora do caminhão e por dentro da betoneira (equipamento utilizado para a mistura de materiais como pedra, areia, cimento e água). O resíduo gerado da lavagem é direcionado a um tanque, e posteriormente para três decantadores (Figura 1), com o objetivo de promover a remoção dos sólidos oriundos da

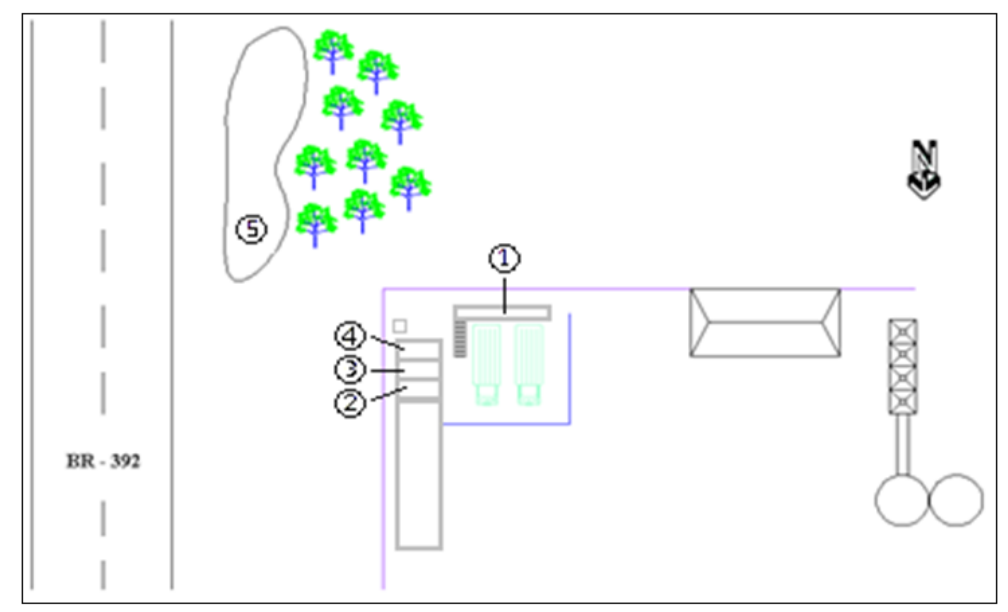

Figura 1 - Representação do atual sistema de lavagem da Empresa estudada. (1) Local da lavagem dos caminhões; (2) primeiro decantador; (3) segundo decantador; (4) terceiro decantador; (5) local de descarte do efluente após passagem pelos três decantadores. 
operação de limpeza dos caminhões responsáveis pela entrega de concreto. Este trabalho constituiu-se da análise de dois tipos de resíduos, sólidos e líquidos, sem ser contabilizada a parte financeira do projeto.

\section{Resíduos Líquidos}

Para a análise dos resíduos líquidos foram coletadas amostras nos meses de junho a outubro de 2009 em cinco pontos pré-definidos. O primeiro ponto (1) corresponde à água limpa proveniente da fonte de abastecimento (poço artesiano) e serviu como parâmetro de comparação (testemunho) dos demais pontos. Nos pontos 2, 3 e 4 estão localizados os decantadores, único sistema de tratamento implantado na Empresa, antes de atingir seu destino final (5) (Figura 1).

As amostras do efluente foram avaliadas de acordo com a metodologia descrita pelo Standard methods for the examination of water and wastewater (APHA; AWWA; WPCF, 1998). Foram analisados os atributos $\mathrm{pH}$, cor aparente, turbidez, oxigênio dissolvido, sólidos totais dissolvidos, coliformes termotolerantes e coliformes totais. Os aparelhos responsáveis pela determinação dos parâmetros foram devidamente calibrados e testados antes de cada análise.

Os valores obtidos pelas análises foram comparados com os resultados da amostra testemunho e os valores determinados pela NBR 13.696 (ABNT, 1997). A avaliação destes parâmetros apresentou a real eficiência dos decantadores instalados na Empresa. Com isto, foi possível verificar a necessidade de se projetar um novo dimensionamento do sistema.

O volume total de água do sistema foi calculado a partir da vazão de água utilizada na Empresa, multiplicado pelo número de lavagens de caminhões feitas por dia, considerando toda a frota utilizada. Este volume foi calculado de acordo com a eq. (1) (IGNÁCIO, 2009).

$$
V=Q \times t
$$

Em que:

$V=$ Volume total do sistema, necessário para o dimensionamento, em $\mathrm{m}^{3}$;

$Q=$ Vazão resultante de todos os caminhões, $\mathrm{em} \mathrm{m}^{3} \cdot \mathrm{h}^{-1}$;

$t=$ Tempo total de lavagem dos caminhões, expressos em horas.

Fez-se necessário o cálculo do reservatório do efluente bruto, destinado ao despejo do efluente após lavagem dos caminhões betoneira. Para o dimensionamento deste reservatório, foi levado em conta o volume total de água utilizada por dia.

Após passar pelo reservatório do efluente bruto, o efluente, então com menos partículas de sólidos, passa por um sistema de decantação. Este sistema foi dimensionado a partir do volume calculado e da vazão do sistema. Fez-se necessário o correto dimensionamento do comprimento e largura do decantador, a fim de se reduzir o arraste de partículas pelo mesmo. O comprimento deste sistema foi calculado por meio da eq. (2), descrita por Jordão e Pessôa (2011). Após ser encontrado o valor do comprimento, pode-se atribuir um valor para a largura do decantador, obedecendo à eq. (3), também descrita por Jordão e Pessôa (2011). A fim de evitar o efeito de turbulência da água ao entrar no decantador, foi adicionado na eq. (2) uma porcentagem variante entre 5 e $50 \%$. Para este caso, aleatoriamente foi atribuído $10 \%$.

$$
\begin{gathered}
L=15(+10 \%) \times h \\
3<\frac{\text { comprimento }}{\text { largura }}>4
\end{gathered}
$$

Em que:

$L=$ Comprimento do decantador;

$h=$ Altura do decantador.

Devido à constatação visual da presença de óleos no efluente gerado na lavagem dos caminhões da Empresa, fez-se necessário a instalação de um sistema capaz de removê-lo. O valor da área de cada câmara do separador foi calculado de acordo com a eq. (4) (TOMAZ, 2005).

$$
\mathrm{A}=\frac{(\mathrm{F} \times \mathrm{Q})}{\mathrm{Vt}}
$$

Em que:

$A=$ Area de cada câmara, em $\mathrm{m}^{2}$;

$F=$ Fator de turbulência;

$Q=$ Vazão do sistema em $\mathrm{m}^{3} \cdot \mathrm{s}^{-1}$;

$V t=$ Velocidade ascensional final da partícula de óleo em $\mathrm{cm} . \mathrm{s}^{-1}$.

Após passagem pelo decantador e caixa separadora de água e óleo, o efluente, passará por um filtro, composto de areia de diferentes granulometrias, pedra brita e manta geotêxtil. A espessura das camadas e altura da caixa de areia foi dimensionada a partir de Di Bernardo e Dantas 
(2005), os quais estabelecem valores mínimos de camadas para filtros rápidos por gravidade.

A água da lavagem de caminhões após tratamento é direcionada até um reservatório, para possível reuso. Este reservatório foi calculado de acordo com o volume inicial, e terá seu início ao final da altura do filtro, a fim de aplicar-se a ação da gravidade, gerando assim menor gasto com bombeamento.

Para o dimensionamento da bomba da água de lavagem de caminhões foram realizados os passos, de acordo com o manual técnico disponível no site das Indústrias Schneider S.A. (2009).

\section{Resíduos Sólidos}

Com a meta de analisar o resíduo sólido retido pelos decantadores, para saber se este possui alguma resistência para integrar a argamassa como material alternativo, foi necessária a incorporação deste em corpos de prova (CP) de argamassa, a fim de se determinar a resistência à compressão do mesmo.

O lodo foi removido do terceiro decantador com a ajuda de pás, sendo colocado em seguida para a secagem ao ar por 24 horas. Após o tempo de secagem, constatada ainda a presença de umidade no resíduo, este foi levado à estufa a $105^{\circ} \mathrm{C}$ por mais 24 horas. Após a secagem, o lodo foi então peneirado, a fim de saber-se a granulometria predominante neste. Três tipos de mistura foram escolhidas aleatoriamente, uma mistura mínima, de $10 \%$ de incorporação de lodo na fração de areia, uma mistura média, com a incorporação de $25 \%$ de lodo, e uma mistura máxima de $50 \%$ de incorporação de lodo na fração de areia.

Para a determinação da resistência à compressão foram pesados três tipos diferentes de areia (todos com a quantidade de $468 \mathrm{~g}$ ), $624 \mathrm{~g}$ de cimento Portland, e adicionados juntamente com $300 \mathrm{~mL}$ de água no misturador mecânico, conforme consta na norma NBR 7.215 (ABNT, 1996).

A massa obtida da mistura foi adicionada em corpos de prova de forma cilíndrica com 10,00 $\mathrm{cm}$ de altura e $5,00 \mathrm{~cm}$ de diâmetro, e base rosqueada de metal. A distribuição da argamassa foi feita imediatamente após a mistura, com o auxílio de uma espátula, colocando-se as porções de argamassa em quatro camadas de altura aproximadamente iguais, seguida por trinta golpes uniformes com um soquete manual. Após o preenchimento dos corpos-de-prova, sua base superior foi emparelhada com uma espátula, de maneira que as bases ficassem paralelas. A cura dos corpos-de-prova foi realizada em períodos de 7,14 e 28 dias, sendo que a cura inicial (primeiras 24 horas) foi feita ao ar, e após desforma, os CP permaneceram o restante dos dias de cura na câmara úmida.

Conforme a NBR 7215 (ABNT, 1996), a fim de corrigir as imperfeições das superfícies dos $\mathrm{CP}$, estes foram capeados com mistura de enxofre quente. Após o tempo de secagem esgotado, estes corpos-de-prova foram rompidos em uma prensa hidráulica. Todo o procedimento após retirada do lodo do decantador da Empresa foi realizado no Laboratório de Engenharia Ambiental e Sanitária do Centro Universitário Franciscano - UNIFRA.

\section{RESULTADOS E DISCUSSÃO}

\section{Resíduos Líquidos}

Os resultados da tabela 1 mostram a média dos valores obtidos entre os meses de junho e outubro de 2009, e comprovam a ineficiência dos decantadores em funcionamento na empresa. Em comparação com a água do poço artesiano utilizado para a lavagem dos caminhões, nota-se o aumento significativo dos parâmetros analisados, como a cor aparente, turbidez, sólidos totais dissolvidos e $\mathrm{pH}$.

Pelos resultados da Tabela 1 pode-se constatar a não conformidade com o manual de conservação e reuso de água na indústria, de Hespanhol et al. (2006), com os parâmetros $\mathrm{pH}$, turbidez, sólidos totais dissolvidos para um reuso de água classe 1, a qual envolve a lavagem de carros e outros usos que requerem contato direto com o usuário. Torna-se necessário por isto a construção de um novo sistema de tratamento do efluente gerado, para possibilitar assim o reuso da água.

Com um cronômetro foi contabilizado o tempo de lavagem dos caminhões, onde se obteve uma média de 6 minutos e 22 segundos por caminhão. $O$ valor foi multiplicado pelo número de caminhões da Empresa, atualmente 8, e pelo número médio de vezes que cada caminhão é lavado por dia, 3. Com isto, foi possível estimar um total de 2 horas, 32 minutos e 48 segundos de funcionamento da bomba por dia. Utilizando como base uma vazão máxima de $7,0 \mathrm{~m}^{3} / \mathrm{h}$, pode-se chegar ao volume de $17.826 \mathrm{~L} /$ dia de água utilizada.

O sistema implantado possui um reservatório dimensionado com $13,45 \mathrm{~m}$ de comprimento, $3,26 \mathrm{~m}$ de largura, e $0,80 \mathrm{~m}$ de profundidade. Este reservatório será a primeira etapa do tratamento do efluente, sendo responsável pela sedimentação de grande parte do material grosseiro presente. $\mathrm{O}$ reservatório deve ser construído de forma para facilitar a entrada de máquinas para a remoção do material sólido decantado neste setor. Para suportar 
Tabela 1 - Média dos valores obtidos para a análise dos decantadores entre junho e outubro de 2009

\begin{tabular}{lccccc}
\hline Parâmetro & P. 1 & P. 2 & P. 3 & P. 4 & P. 5 \\
\hline $\mathrm{pH}$ & 7,18 & 12,00 & 11,99 & 11,99 & 11,72 \\
Cor aparente (Pt-Cb) & 1,34 & 37,38 & 23,78 & 19,9 & 18,72 \\
Turbidez (NTU) & 1,32 & 67,16 & 63,46 & 61,28 & 58,14 \\
Sólidos Totais Dissolvidos (mg/L) & 89,0 & 2188,2 & 1558,4 & 2546,2 & 2350,7 \\
Oxigênio Dissolvido (mg/L) & 10,338 & 8,496 & 7,888 & 6,916 & 9,415 \\
Coliformes totais/fecais(NMP/100ml) & 0 & 0 & 0 & 0 & 0 \\
Cloro Residual (mg/L) & 0 & 0 & 0 & 0 & 0 \\
\hline
\end{tabular}

o volume útil estipulado, deve-se construir esta etapa de tratamento com $0,90 \mathrm{~m}$ de altura na parte mais profunda, até a tubulação de passagem do efluente à próxima etapa de tratamento, tendo um comprimento total de $9,00 \mathrm{~m}$, além desta largura, de $3,26 \mathrm{~m}$, perfazendo um total de aproximadamente $20,50 \mathrm{~m}^{3}$.

De acordo com a baixa vazão na Empresa, faz-se necessário apenas um decantador, o qual foi dimensionado a partir da velocidade de sedimentação das partículas com diâmetro menor do que $0,10 \mathrm{~mm}$, que está em torno de $0,16 \mathrm{~m} / \mathrm{s}$. Aplicando as equações (1) e (2), foi encontrado para o sistema de tratamento um decantador com 10,00 $\mathrm{m}$ de comprimento, $0,70 \mathrm{~m}$ de altura útil e 2,50 m de largura. A fim de não parar o funcionamento do sistema nos dias de limpeza, 2 decantadores são igualmente instalados, um ao lado do outro, fazendo parte de um sistema de decantação em conjunto.

Utilizando dados referenciados por Tomaz (2005), o qual dá valores de Fator de Turbulência
(F) em torno de 1,74, e velocidade ascensional (Vt) em torno de $0,002 \mathrm{~m} / \mathrm{s}$, foi encontrado o valor da área da caixa separadora de água e óleo, que fica no meio do sistema, onde ocorre a separação propriamente dita, que é de $1,70 \mathrm{~m}^{2}$. Para a altura útil do sistema foi utilizado o valor mínimo permitido, que é de $0,90 \mathrm{~m}$. A água passa de tanque para tanque por meio de um sistema de sifão instalado com tubulações em PVC de $100 \mathrm{~mm}$, distantes $0,30 \mathrm{~m}$ do fundo da caixa.

O filtro foi dimensionado com $1,00 \mathrm{~m}$ de comprimento, $1,50 \mathrm{~m}$ de largura, e altura total de $1,00 \mathrm{~m}$, contando com a altura livre acima da primeira camada filtrante. A camada suporte, também chamada de fundo falso, composta por pedra brita número 1 , terá altura de $0,15 \mathrm{~m}$. Junto com esta camada de pedra brita são necessários coletores da água filtrada, os quais são compostos por tubulação em PVC de $50 \mathrm{~mm}$, interligados por outra tubulação central e assim escoados em PVC de $100 \mathrm{~mm}$ até a próxima etapa do sistema. Acima desta camada deve haver uma manta geotêxtil,

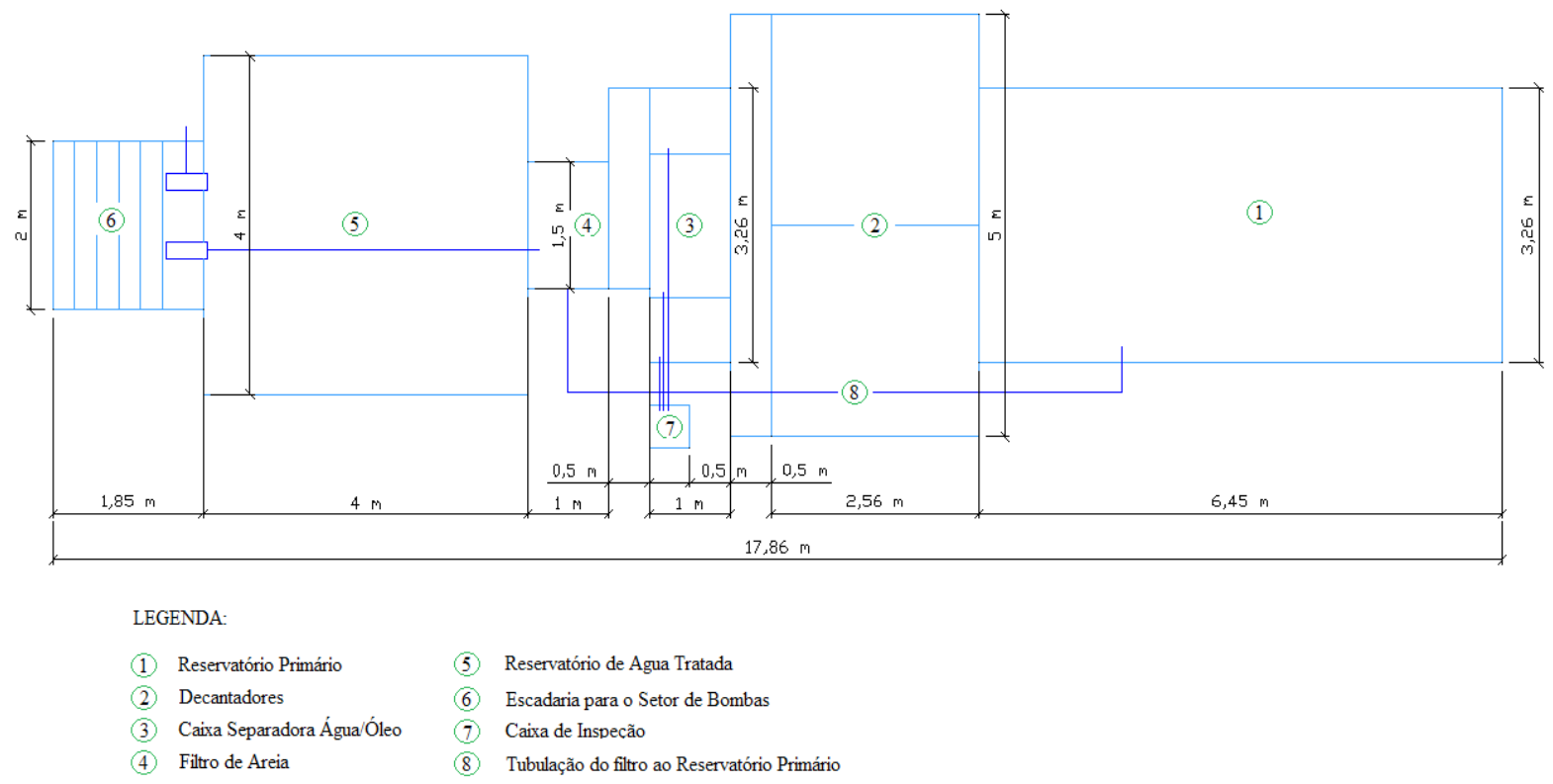

Figura 2 - Vista superior do modelo final do anteprojeto. 
que recobrirá toda área horizontal desta camada. A camada de areia retida em peneira malha 10 terá altura de $0,25 \mathrm{~m}$. Acima deve haver outra camada de areia, porém mais fina, passante em peneira número 10 , de $0,20 \mathrm{~m}$. Entre estas duas camadas de areia haverá novamente manta geotêxtil A primeira camada contará com pedra brita número 1 , e terá $0,10 \mathrm{~m}$ de altura. Acima destas camadas, deve haver uma altura livre de $0,30 \mathrm{~m}$, para futura lâmina de água.

Este reservatório foi dimensionado a partir do volume total do projeto, e possui $4,00 \mathrm{~m}$ de comprimento e $4,00 \mathrm{~m}$ de largura, com profundidade de 1,50 m de altura útil para a água tratada. A fim de projetar um sistema que seja conduzido pela ação da gravidade, este reservatório começará a partir do final do filtro.

Para o dimensionamento da bomba foi adotado o parâmetros de rendimento da bomba como o global, em $70 \%$. Com isto, obteve-se então valores de vazão: $7,0 \mathrm{~m}^{3} / \mathrm{h}$, diâmetro de recalque: $40 \mathrm{~mm}$, diâmetro de sucção: $50 \mathrm{~mm}$, altura manométrica total: $7,81 \mathrm{~m}$ e potência do motor de $1 \mathrm{CV}$.

$\mathrm{O}$ anteprojeto (Figura 2) dimensionado neste trabalho teve por objetivo reduzir os impactos ambientais do estabelecimento, tornando o sistema de lavagem da Empresa fechado, e poupando em torno de 18 mil litros de água de poço artesiano por dia.

\section{Resíduos Sólidos}

A granulometria do lodo, após a secagem e peneiramento, variou de $0,3 \mathrm{~mm}$ a menores que $0,15 \mathrm{~mm}$, de acordo com a tabela 2 . Com este resultado, foi possível classificar os sólidos presentes no lodo como muito fino por se tratar de material retido em grande parte na peneira número 100 e até passante desta.
Os corpos-de-prova foram moldados, numerados, medidos, capeados e rompidos com idade de 7,14 e 28 dias, obtendo-se os resultados de resistência à compressão média apresentada na figura 3. Os corpos-de-prova de argamassa com $10 \%$ de lodo incorporado na fração fina da areia obteve para o sétimo dia 19,58 $\mathrm{MPa}$, para o décimo quarto dia $22,76 \mathrm{MPa}$, e para o vigésimo oitavo dia 29,03 MPa. Enquanto que os CP contendo $25 \%$ de lodo incorporado apresentou para o $7^{\circ}$ dia 18,89 MPa, 23,04 MPa para o $14^{\circ}$ dia, e 22,56 $\mathrm{MPa}$ para o $28^{\circ}$ dia. Por último, os $\mathrm{CP}$ contendo $50 \%$ de adição de lodo na argamassa resultou em $15,56 \mathrm{MPa}$ ao $7^{\circ}$ dia, $16,09 \mathrm{MPa}$ no $14^{\circ}$ dia, e $18,48 \mathrm{MPa}$ no $28^{\circ}$ dia.

Tabela 2 - Porcentagem retida de lodo em cada peneira.

Washington (2009) encontrou resistências médias de $17,7 \mathrm{MPa}$ aos 28 dias com $10 \%$ de substituição de areia por resíduo de mármore,

\begin{tabular}{ccc}
\hline \multicolumn{2}{c}{ Peneiras } & Determinação \\
\hline $\mathbf{N}^{\mathbf{0}}$ & $\mathbf{m m}$ & \% retida \\
4 & 4,8 & 0 \\
8 & 2,4 & 0 \\
16 & 1,2 & 0 \\
30 & 0,6 & 0 \\
50 & 0,3 & $5,9 \%$ \\
100 & 0,15 & $77,3 \%$ \\
Fundo & $<0,15$ & $16,8 \%$ \\
\hline
\end{tabular}

utilizado na fabricação de lajotas. No presente trabalho com $10 \%$ de substituição do lodo gerado nos decantadores obteve-se uma resistência de 29,03 MPa. Por comparação o lodo incorporado na argamassa poderia ser utilizado na fabricação de lajotas.

Segundo Godoy et al (2008) utilizando

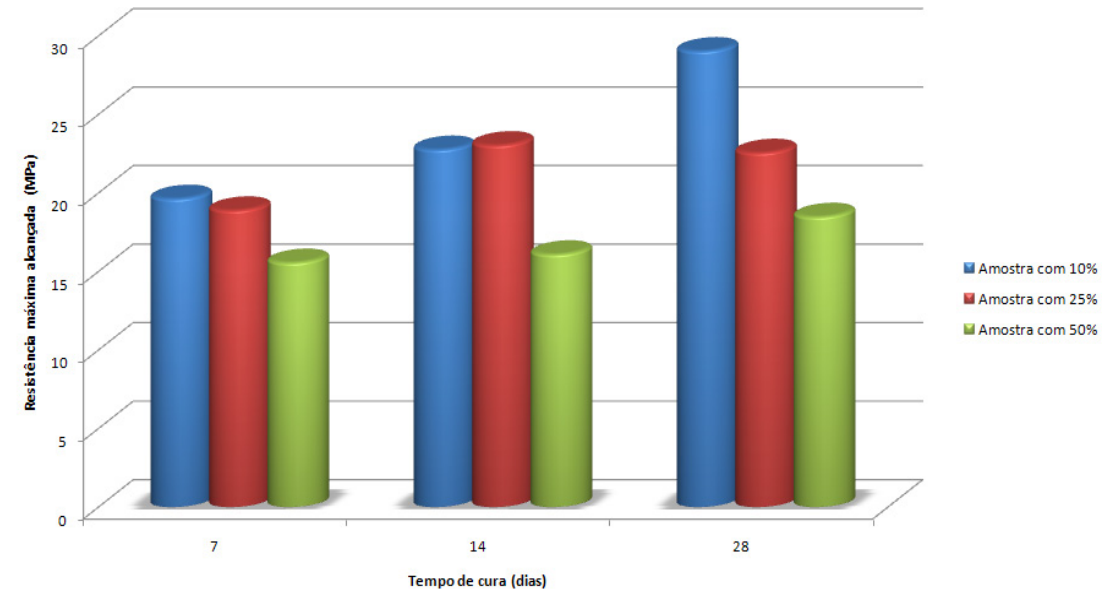

Figura 3 - Tensão em MPa dos corpos-de-prova. 
sucata de vidro na fabricação de argamassa, com substituição de $25 \%$ da areia pela sucata de vidro encontrou-se resistência aos 7 dias de 20,42 e aos 28 dias de 30,19 $\mathrm{MPa}$. Os autores relatam ainda sobre os traços de referência, com 22,84 Mpa aos 7 dias e 31,96 Mpa aos 28 dias. O lodo gerado a partir dos decantadores, com $25 \%$ de substituição alcançou uma resistência de 18,89 $\mathrm{MPa}$ ao $7^{\circ}$ dia, e resistência final no $28^{\circ}$ dia de $22,56 \mathrm{MPa}$, portanto resultados inferiores tanto ao traço de referência como ao traço de argamassa com a adição de sucata de vidro.

Enquanto Gomes e Silva (2006) relatam sobre as especificações do cimento CP IV-32, na qual a resistência à compressão para a idade de 7 dias deve ser maior do que 20,00 Mpa, e aos 28 dias maior ou igual a $32,00 \mathrm{MPa}$.

É importante salientar que a resistência mínima exigida no caso de concreto estrutural é um valor acima de $15 \mathrm{MPa}$. Já para pavimentação de circulação de pedestres e veículos leves a resistência deverá ficar com um valor acima de 7,5 MPa (PAREJA et al, 2008). Portanto, os valores encontrados com a incorporação do lodo na argamassa mostram uma boa resistência já na fase inicial de cura, e podem ser utilizados para concreto em locais que exijam pouca resistência.

Os resultados comprovam que a incorporação de apenas $10 \%$ do lodo gerado nos decantadores da Indústria pode gerar uma alta resistência inicial. Ao sétimo dia de cura, esta porcentagem igualou o que as outras duas porcentagens (25 e $50 \%$ ) obtiveram ao final de 28 dias, suportando então ao final de 28 dias uma tensão e carga máxima na prensa muito superior.

De acordo com a Secretaria dos Transportes de São Paulo - SP (2010), o concreto empregado na moldagem dos meios-fios, sarjetas e sarjetões deve possuir resistência mínima de $20 \mathrm{MPa}$ no ensaio de compressão simples, aos 28 dias de idade. Já a fabricação de lastros de concreto exige no mínimo uma resistência de $15 \mathrm{MPa}$.

\section{CONCLUSÃO}

Com este trabalho foi possível verificar a necessidade de melhoria no sistema de descarte do efluente da lavagem de caminhões da concreteira estudada. O despejo incorreto deste efluente em vala nas proximidades pode trazer sérios riscos ao ambiente local, como a diminuição da infiltração no solo, o aumento excessivo do $\mathrm{pH}$ e a contaminação do lençol freático. O efluente apresentou uma grande disparidade entre a amostra testemunho (poço artesiano) e a amostra no final do sistema de tratamento. Em vista disso, o anteprojeto foi dimensionado de acordo com a literatura pesquisada e necessidades atuais da Empresa Concreteira estudada, e certamente aumentará a eficiência de tratamento do efluente gerado.

Em relação aos resíduos sólidos, a incorporação do lodo gerado na indústria pode significar a redução de um impacto ambiental, contribuindo assim para um desenvolvimento sustentável, onde não será desperdiçado nenhum material gerado. A resistência atingida no $28^{\circ}$ dia pelo corpo-de-prova com 10\% de lodo incorporado, 29,03 MPa, mostra-se um ótimo resultado para a sua adição em lastros de concreto, e pode ainda ser incorporado em meios-fios, sarjetas e até em ruas e estradas que exijam maior controle de resistência. Embora com resistência final atingida menor, os valores obtidos para os corpos-de-prova com $25 \%(21,51$ $\mathrm{Mpa})$ e $50 \%$ (17,78 Mpa) de adição de lodo são valores preliminares satisfatórios.

\section{REFERÊNCIAS}

ABNT - ASSOCIAÇÃO BRASILEIRA DE NORMAS TÉCNICAS. NBR 7215: Cimento Portland - Determinação da resistência à compressão. Rio de Janeiro, 1996.

APHA; AWWA; WPCF. Standard methods for examination of water and wastewater. 20. ed. Washington D.C, 1998.

DI BERNARDO, L.; DANTAS, A. Métodos e técnicas de tratamento de água - São Paulo: Editora Rima. V. 2, 2005.

DIAS, J.F. A construção civil e o meio ambiente. Disponível em: <http://www.feciv.ufu.br/palestras/ Palestra3.pdf>. Acesso em 13/09/2010.

FONTENELE, S. B.; GUIMARÃES, J. L. S.; SABIÁ, J. R. Legislação ambiental versus tecnologia limpa: uma reflexão junto ao setor industrial do Triângulo Crajubar - CE. In: Encontro Nacional de Engenharia de Produção ENEGEP, XXVI, 2006, Anais... Fortaleza CE. Disponível em <http://www. abepro.org.br> Acesso em 15/09/2010.

FUNDAÇÃO VANZOLINI. Produção e Tecnologias Limpas. Boletim Fundação Vanzolini. Ano IX. Número 42. Departamento de Engenharia de Produ- 
ção - Escola Politécnica da USP, 2000.

GODOY, J. et al. Utilização de sucata de vidro na fabricação de argamassa. XII Simpósio de Ensino, Pesquisa e Extensão, SEPE - 2008, UNIFRA, Santa Maria - RS.

GOMES, A. O.; SILVA, V. S. Caderno de Aulas Práticas (ENG-101 Materiais de Construção II). Universidade Federal da Bahia. Escola Politécnica. DCTM. Salvador, 2006.

HESPANHOL, I. et al. Manual de Conservação e Reúso de Água na Indústria. Rio de Janeiro: DIM, 2006.

IGNÁCIO, R. F. Curso básico de mecânica dos fluídos. Disponível em: <http://www.escoladavida. eng.br/mecflubasica/Apostila/Unidade\%203/Primeira\%20aula\%20da\%20unidade\%203.pdf>. Acesso em 3 de novembro de 2009.

INDÚSTRIAS SCHNEIDER SA. Manual técnico. Disponível em: <http://www.schneider.ind.br/> Acesso em 7 de dezembro de 2009.

JORDÃO, E. P.; PESSÔA, C. A. Tratamento de esgotos domésticos. 4. Ed. Rio de Janeiro: ABES. Rio de Janeiro - RJ. 2011. 1050 p.

PAREJA, J. A. M. et al. Substituição da areia por polietileno de alta densidade (PEAD) na produção de concreto. Vi Simpósio de Engenharia Ambiental, 2008, Serra Negra - SP.

SCHENINI, P. C.; SILVA, A.; SILVA, F. A.; RENSI, F. Gestão da produção mais limpa: um estudo de caso. In: SIMPÓSIO DE ENGENHARIA DE PRODUÇÃO, 12., 2005, Bauru. Anais ... Bauru: UNESP, 2005. p. 1-12. Disponível em: <http://www.simpep. feb.unesp.br>. Acesso em 18/09/2010.

Secretaria dos Transportes de São Paulo - SP. Resistência do concreto a compressões. Disponível em: < http://www.transportes.sp.gov.br/v20/default.asp>. Acesso em 18/09/2010.

TOMAZ, P. Caixa de retenção de óleos e sedimentos. 2005. Disponível em: <http://www.hidro.ufcg. edu.br/twiki/pub/NormaAguaDeChuva/NormaDownloads/Capitulo07-Captaaodeoleosegraxas. pdf> Acesso em: 08/12/2009.

WASHINGTON, A. M. Utilização do resíduo de corte de mármore e granito em argamassas de revestimento e confecção para piso. Disponível em: $<$ http://residuosindustriais1.locaweb.com.br/arquivos/Artigos/utilizacao_do_residuo_de_corte_de_ marmore.pdf> Acesso em 12/09/2010. 